$\S=-1$

\title{
Healthy Life-Style of Students: Sociological Approach
}

\author{
Valery Panachev", Leonid Zelenin, Anatoly Opletin, Aleksandr Legotkin, Viktoria Ovchinnikova \\ Department of fisical culture, Perm national research politehnik university (Perm, Komsomol, pr., 29, Russia) \\ *Corresponding author E-mail: bpanchev@yahoo.com
}

\begin{abstract}
The ancient Greek philosopher Plato called movement as "salutary part of medicine", while writer and historian Plutarch - as "storehouse of life". Do we always apply efforts in order this "storehouse" be full? Today in the age of scientific-technological progress largescale utilization of manual labour has been practically disappeared and there has been opened the door for the so called "diseases of the century". The analysis of the results of students' health and healthy life-style problems study has been presented in the article. The role of physical culture and of the department of physical culture in this process has been determined. The ways of university's educational environments resources stirring up for this problem solution have been outlined. Many people try to fully protect themselves against physical activity. They think that the less physical activity the healthier they become. Many students try to make their physical activity less thereby breaking their health. In any ways they try to obtain health certificates in order not to attend physical culture lessons and practically in all cases they get moral support of parents and what is the worst of doctors.
\end{abstract}

Keywords: students, health, sociological study, healthy life-style, physical culture, sport; university, physical activity.

\section{Introduction}

It is known that continuous mental stress and overwork without physical relaxation provoke hard functional disorders, degradation and approach of premature old age. Many scientists [1-14] determined that regular physical exercises reduce cholesterol amount in blood which promotes the development of atherosclerosis. Simultaneously activation of anti coagulation system preventing thrombus appearance in blood vessels occurs. At the expense of moderate increase of total number of potassium ions and decrease of sodium ions in blood myocardium contractile function is normalized. Adrenal glands release "hormone of good mood" in blood. Taking this fact into consideration it is no wonder that, for example, in Switzerland in small towns situated in mountains where citizens can only move and run there registered no cases of cardiovascular diseases. Such long uniform physical activity as run strengthen immune system at the expense of activation, renovation and increasing of white corpuscles' composition, stimulate blood formation increasing hemoglobin in blood. Medical observations showed that regular run activity can influence the renovation of digestive cells, inhibit the process of muscular tissue substitution by adipose one and normalization of cholesterol amount in blood protect both atherosclerosis development and canceration. NewYork insurance company observed 100 thousand clients and discovered that mortality from "the diseases of civilization" of physical active people is three times less than of the rest part of population. Physical exercises are the important means of carbohydrate metabolism disturbance protection. For example, doctors of one of the Swedish towns were able to help 100 prediabetic people out of risk zone by means of sport training only. It is obvious that the possibility of physiological reserves mobilization during intensive physical activity is great. It has been determined that volume of breath per minute grows 20-30 times in comparison with the state of rest, frequency of pulse rises from 50-60 to 240 blows per minute, and arterial pressure - from $120 / 80$ to $200 / 40 \mathrm{~mm}$ of column of mercury. Under the influence of physical exercises blood supply of muscular tissue (including cardiac muscle) becomes better. During physical activity it could open 2500 capillaries on $1 \mathrm{~mm}$ of muscle cross section against $30-80$ ones in the state of rest. The greatest increase of capillaries amount occurs in the cortex of frontal lobe. Simultaneously the increase of capillaries' length and density of capillary network was registered. The urgency of the given research is becoming greater from year to year as it has tremendous importance in the development of world science and in improvement of peoples' health.

\section{Methods}

Experimental program of physical culture and technology of its realization was developed on the base of carried out research. The goal of experimental program is the strengthening of educational function and rebuilding of organizational forms of physical training both at lessons and during students' independent activity. Experimental work was organized with the aim to achieve this goal. The control group (45 persons) included the first year students trained according to the traditional form of education. Control group consisted of 45 students who were trained according to the experimental program. The experiment was conducted during the academic year. At the end of the year there were made control tests (sections).

\section{Survey of Literature}

Analysis of the world social cultural and educational tendencies shows that in the last years the object of great attention of society and the subject of inter disciplinary research in many developed countries became different aspects of human behavior in respect of their health. Different systems of healthy life-style education are being tested $[3,4,7,9,10,14]$. The commonly accepted opin- 
ion of specialists in the field of physical culture consists in the necessity of students' physical culture system reformation on the base of the principles of humanistic pedagogy, ethics and psychology aimed at self-development of the trained individuals. The analysis of students' physical culture system allows stating the number of its main contradictions which are characterized by:

- the presence of physical culture innovative programs and nondeveloped adequate technologies of their realization;

- the necessity of students' physical culture level of scholarship and the lack of teachers' preparedness to its development;

- the importance of students' manifestation of the subjective position in physical culture educational process and poor utilization of pedagogical technologies developing individuality and providing its manifestation and formation;

- aiming of educational process at physical culture formation and utilitarian-applied orientation of estimation criteria of success in educational material mastering stipulated by the physical culture program.

During the analysis of the organization of physical culture studies at universities in whole as well as students' attitude to these studies the following tendencies should be mentioned:

- low students' interest to physical culture studies, especially those which are conducted in traditional form; poor account of needs, motives and value orientations of students in transformation of their physical nature;

- insufficient readiness of students, especially of the first year students, to turn to the organization of independent forms of physical culture activity, to the strengthening of their health and enlargement of creative longevity;

- lack of correspondence between the competence level of teacher of physical culture and the modern requirements; this discrepancy appears in insufficient professional readiness to master new forms of physical exercises knowledge, modern technologies demanding the mastering of individual systems, means, methods and forms of their organization;

- the lack of teaching and methodological literature on students' individual self-development by means of physical culture.

All these fact induced us to develop sociological analysis of student by means of physical culture.

\section{Results}

\subsection{The goal of study}

Familiarization of students with regular studies of physical culture and sport, motion activity, improvement of functional ability of organism by means of introduction innovative pedagogic system aimed at individual development in students' educational process. In the process of educational work and functioning of pedagogical system at university the solution of the following problems is carried out: improvement of students' physical development, achievement of high training level, functional state and training organism; teaching of moral, esthetic, motion culture, of aspiration for health, beauty, love and harmony; development of need for self-realization, self-development of individual, breeding of selfrespect and sense of respect to other people, formation of readiness to self-development, self-developing activity, objective selfappraisal; moral development, correction of value scale; mentality, formation of visions and ideas. It is obvious that oxygen feeding of brain cells promotes improvement both of physical and mental efficiency. In other words physical culture substantially assists mental activity. It coincides with Aristotle's affirmation about the fact that thoughts flow quicker when the body is warmed up by the walk. As it is known he conducted lessons while walking with his pupils. And on the contrary, the lack of muscular movements makes our muscles weak and our brain open to cerebral affection. In our age of atom and cybernetics intellectual work more and more displaces physical one or become closely intertwined with it. But as many scientists think hard mental work demands very good physical training of a man. "All my life, - wrote academician I.P.Pavlov, - I liked mental work as well as physical one, and perhaps the second I liked more. I especially felt to be satisfied when the last brought any good guess, i.e. joined head and hands". P.F.Lesgaft, the founder of physical training in Russia, distinguished doctor and teacher emphasized many times that discrepancy of weak body and developed mental activity - "body and spirit" - will sooner or later negatively influence general condition and health of a man. "Such harmony disturbance is not stayed unpunished - it inevitably carries impotence of external manifestation: there could be thought and understanding but no proper energy for successive control of ideas and their persistent application in practice", - he wrote. Many foreign scientists [1-14] believe that special "mental gymnastics" helps to support high intellectual efficiency. Such gymnastics concerns the so called headstand. This exercise together with legs bending and extension in knee and hip joints not only intensifies brain cells blood supply, reinforces vessels but promotes venous blood outflow from lower extremity and pelvic organs, i.e. they are the important means of varicose, piles and lithonephria prevention. In order to save from illnesses and suffering it is necessary to modify one's own individuality. Such even motion as running strengthens immune system at the expense of activation, renewing and increasing the number of white blood cells. Two and a half thousand years ago in Hellas there were carved the following words on huge rock: "If you want to be strong - run, to be beauty - run, if you want to be clever - run". Running is one of the most efficient means for good health. It is the necessary factor for organism. All organs of our body were formed in conditions of constant motion during millions of years. When the motion is restricted the functions of organs are violated. As Horace said, if you don't run being healthy you will run being ill. Practically healthy man should run minimum 15-20 minutes a day covering the distance of about 3-4 km. Old age is not an obstacle for running. For example, Joe Dickens, ever known athlete who was named by journalists as "grandpa of running" run about $7 \mathrm{~km}$ every Sunday when he was 90 years old. Sport longevity of Larry Lewes, the American man is more surprising. When he was 102 years old he run $10 \mathrm{~km}$ every morning. The distance of $91 \mathrm{~m}$ was covered by him during $17,3 \mathrm{sec}$. $(0,5 \mathrm{sec}$ faster than the year before). Philippid, the best runner of ancient Greece who covered the distance of $42 \mathrm{~km}$ and $195 \mathrm{~m}$ in order to inform about the victory of the Greeks over the Persians in 490 $\mathrm{BC}$ is often mentioned in literature. According to other sources of information he covered the distance about $200 \mathrm{~km}$. If it we take into consideration that after this running he took part in the battle we can only be surprised by his stamina. Despite the usefulness of running it should be done under control according to the recommendations developed by specialists. Otherwise the result could be quite sad. For example, James Fix, the initiator of mass passion for running in the USA, died suddenly at the age of 52 during the regular jogging. In the opinion of doctors the cause of his death became the inherited propensity for myocardial infarction, the presence of such risk factors as often smoking and excess weight. Moreover, he went jogging for 30 minutes 3-4 times a week.

We know more facts of death because of myocardial infarction caused by running overdose. This sad statistics include Alexandro Beverini who was 45 years old and the head of department of therapy in Kirov Medical institute professor V.S.Nesterov who was 75 years old. But at the same time there is an example of Larry Lewes, an American waiter from San-Francisco who died at the age of 106 and a day before his death he covered a distance of 10 $\mathrm{km}$. According to pathologists his heart and blood vessels were excellent. So, movement is the essence of life. Movement is the base of health. O.K. Antonov, the well-known aircraft designer, wrote that real physical culture is the reasonable attitude to the organism - receptacle of our intelligence - all 24 hours. We emphasize: not morning exercises, even not sport lessons several times a week but constant round-the-clock culture of attitude to oneself, optimal physical life-style make human existence of fullvalue. 


\subsection{Statement of the problem}

Qualitative professional training of students at university is impossible without their energetic educational and labour activity. Economic and social reasons which do not allow making the period of education longer enforce to intensify it. This process requires students' will mobilization, their psychophysical, moral and physical power. However, today it is impossible to put question about restriction of increasing tension in the process of education. So, if it is impossible to free students from psycho emotional and physical tension (and it is probably worth seeking to this), then it is necessary to increase resistance of adaptive body mechanisms to emotional stresses and to streamline their educational activity. It is necessary to teach students healthy life-style for which unity and reasonability of self-organization and self-discipline, selfregulation and self-development processes are typical. These processes are oriented to full-fledge realization of one's own essential forces, gifts and abilities.

Formation of citizens' healthy life-style (HLS) as the goal of national importance and security is specially updated in the modern world practice as by 2018 it will have been necessary to provide "mortality reduction" at the expense of "arrangements aimed at healthy life-style formation". Different approaches to the realizing of "healthy life-style" phenomenon allow concluding that it unites all things which promote fulfillment of professional, social and everyday functions in the optimal for men's health conditions and orients individual activity to forming, keeping and strengthening both personal and social health. We carried out sociological research of Students' Healthy Life-style which showed young people's attitude to themselves, to their mode of life and health in whole.

\subsection{Analysis of HLS study}

Recently there has been appeared special attention to the students' HLS. This fact tells about government and society concern of the university graduates' health, of the incidence rate in the process of professional training, of labour activity reduction. So, it is necessary to consider health and HLS as one of the important educational value os society and student's personality [14].

\subsection{Students' health and university educational envi- ronment}

Studying at university is a complicated and quite long process having the number of characteristic features and making high demands for psyche and physiological functions flexibility of young people. After admission to university there happens the break of yesterday's schoolchildren vital stereotypes. The initial period of training plays sufficient role in the development of adaptive and compensatory mechanisms. Student's health and ailment depends to a great extent on this period. On the base of neurologic status and cardiovascular system study of 2142 first year students there were selected 4 groups: practically healthy students - 1509 persons $(70 \%)$, students with raised blood pressure - 254 persons $(11 \%)$, students with phenomenon of hypotension - 90 persons (4\%), students with functional neural disorder - 289 persons (13\%) In total the second, third and fourth groups involved $29 \%$ of the first year students having problems in the level of health. Analysis of patients' files showed that most students taking the academic holidays $(83 \%)$ began to ill during the first or second years of studies. The reasons of their illness appeared to overpressure and overload in the process of training [1]. Diagnostics of students' level of health carried out at university showed that only $7 \%$ of tested students had good locomotive system, $28 \%$ of students had functional disorders and $64 \%$ of students were in pre- and pathological state. Only $7 \%$ of tested students had normal digestive system, $85 \%$ of students had functional disorders and $6 \%$ of stu- dents were in pre- or pathological state. In whole this study showed the presence of subjective complaints and objectively approved pathologies in one or several systems and organs of the most number of tested students. None of the tested students could receive conclusion "absolutely healthy" and only $15 \%$ of them could be characterized as "symbolically healthy" (i.e. they had only functional disorders). Study of psyche component of students' health showed considerable cases of asthenia depression and a great number of functional neuropsychic disorders. Only $21 \%$ of 312 students of natural sciences and humanities presented stable mentality. Even in the 1980s there were marked the growth of students' nervous system functional disorders - the so called inbetween mental state. Disorders of students' nervous system increase from the first to the third year of studies, and boys in technical universities are in poor health more often. Nervous-psyche disorders develop against the background of social nonadaptive syndrome, mental overloading in the period of passing examinations, on the base of inter-personal conflicts [1].

Comparing the results of studies made in different regions of the country it is observed stereotyped picture of students' health worsening during their study at university subject to ecological situation and climatic and geographical conditions [1, 2, 4, 9, 10]. Attitude to one's health is provided by objective conditions including education. It becomes apparent in actions, emotional experience and verbally realized opinions and judgments of people concerning factors influencing their mental and physical condition. Empirical criteria of relation to health can serve the degree of conformity between person's actions and requirements for healthy life-style as well as standard requirements of medicine, sanitation and hygiene. In the advanced opinions and judgments the level of individual awareness and competence is presented. Relation to one's health includes self-appraisal of own physical and mental state which is the indicator and regulator of person's behavior.

Analysis of literature $[5,11]$ showed that in hierarchy of values students consider health to be in the leading positions. Thus, according to different sources of information (average indicators were taken) health as universal value was highly assessed by $75 \%$ $( \pm 5,0)$ of boys and girls (girls' assessment was higher). Meanwhile health is correlated with the other universal values: happy family life, comprehensive and balanced development, mental ability, etc. At the same time it is mentioned that the value of health as the means of other goals achievement (achievement of material welfare, career, etc.) appears to be more important for students than the value of health as the means of long and valuable life.

\section{Discussion}

According to our results (there were tested 380 students of different years of study) the main bulk of young people do not seriously relate to their health. Thus, there were given the following answers to the question if the students watch over their health: regularly watch $-13 \%$ of boys, $23 \%$ of girls; watch from time to time $-37 \%$ of boys, $39 \%$ of girls; begin to watch only in case if feel unwell $50 \%$ of boys, $38 \%$ of girls. Students do not know their pulse rate in the rest, their blood pressure. Other researchers mark similar students' relation to their health [1-2]. As it was mentioned above, most students think that their health is the necessary condition for the life of good quality, but only small part of them considerably attend their health. This fact leads to the appearance of one more contradiction between verbal awareness of health value and energetic voluntary activity concerning its keeping and strengthening. For example, E.A.Zhitnitskaya et.al mentioned that many students with chronic pathology of respiratory apparatus smoke and are not going to come off with cigarettes. Those who have chronic illness of gastrointestinal tract break the diet and those who suffer from locomotor apparatus disease neglect exercise therapy [1].

The necessary and main precondition for health maintenance is the healthy life-style as the standard model, system of common conditions, arrangements promoting health strengthening and keeping. 
Numerous researches made possible to conclude in theory and in practice that life-style influence human health for $50 \%$, environment influence it for $25 \%$, heredity effect health for $15 \%$ and medicine - only for $10 \%$. Students highly assess healthy life-style but their real behavior contradicts expressed opinion and judgment of HLS value. There were received the following answers for the question if the students lead a healthy life: in general yes - $24 \%$, rather yes than no $-18 \%$, rather no than yes $-38 \%$, found difficulty in replying $-18 \%$. Analysis of the results show that more than $50 \%$ of students do not lead the main elements of life activity regime, they have no formed purpose of rational time planning. They violate the norms of mental activity, of everyday life, of meals, of staying in fresh air and doing physical exercises. It is known that modern system of education demands for considerable students' mental activity, but the results of testing show that only $42 \%$ of students learn systematically and independently while all the rest study from time to time. Physiologists determined that the best time for beginning independent preparation for studies is the afternoon, 16 p.m. During our study we revealed that $35 \%$ of students fulfill their tasks in definite time, all the rest do this work in any time of a day. Considerable part of tested students - 55\% begin to learn the material from 20 to 22 p.m. and some of students start to do their work even later which leads to the poor preparation.

In order to support mental activity on high level and to maintain health it is necessary to alternate studies with the rest correctly. The best rest is sleeping in definite time not less than 7-8 hours. But $40 \%$ of students do not lead sleeping regime, many of them feels shortage of it as they go to bed after midnight or even later which influence negatively their mental efficiency. Numerous studies of physiologists, psychologists, hygienists and specialists of Pedagogics show that the regime of motion activity considerably influences the quality of students' education. It has been stated that the most suitable motion regime is equal to 6-8 hours a week. This motion regime is maintained only by $26 \%$ of tested students while most young people $-75 \%$ - do physical exercise during 2 4 hours including physical culture studies at university. Physical culture lessons are attended regularly $43 \%$ of students, all the rest - 56\% of students attend these lessons from time to time. And only small part of students does physical exercises independently. In order to answer the main question, namely, what we can do to achieve the general goal - the growth of the efficiency of students' HLS formation process - the investigation of already available information on this problem both in theory and in practice is required. Without this knowledge it is impossible to define the mechanism of the given process control, the choice of means and methods of the goal-oriented actions. Theoretical foundation of this problem solution has been given by sociological, medico biological, psychological and pedagogical research. Scientists discuss general problems of students' health and mode of life (N.P.Abaskalova, N.A.Agadzhanyan, A.M.Gendin and others); study the influence of different factors on students' HLS formation (V.Buylov, T.A.Ivanova, V.G.Nikolaev and others); study the level of students' knowledge in this subject (A.V.Belokon, Yu.M.Politova, G.S.Sovenko and others).

The tendency of this problem solution reconsideration, the ways of its solving reflecting the replacement of the accent from the sphere of medicine to pedagogics have been outlined (N.P.Abaskalova, R.I.Aizman, E.N.Vainer, G.K.Zaitsev, E.M.Kazin, L.G.Tatarnikova and others). Such tendency is connected with the fact that the main "risk factors" have behavioral basis, so the mode of persons' life plays an important role in keeping and strengthening of his health. In the rational organization of such life-style sufficient importance has education and physical culture.

In the opinion of many scientists theory and practice of public health will inevitably follow the concept of attack, the concept of physically cultural life-style. According to the forecasts of medical science representatives the most important element of this will be goal-oriented growth of human organism's systems and functions efficiency by means of physical culture $[3,4,6]$. Physical culture unites many components: culture of motion activity, conditioning to the cold, breathing, mills, massage, meditation, utilization of natural factors. Just in this respect it is necessary to speak about physical culture. Then it is obvious that physical culture is the basis and driving force of healthy life-style formation. It is necessary to mention that realizing of physical culture role as one of the leading factors of students' HLS formation serves the tendency of insistent search for efficient pedagogical activity, approaches, and technologies of students' HLS formation by means of physical culture. Monographs, teaching aids, methodological materials are published; doctors' and candidates' theses are defended. All these materials contain theoretical and practical prerequisites of successful solution of the given problem [7, 12, 13].

In the papers devoted to the different aspects of this problem it is specially mentioned that the attempts to revive at universities physical-cultural, health-improving and sport-mass work by means of the old organizational forms and methods do not give necessary results as a rule. Professionals state that unfortunately physical culture studies at universities are aimed at the problems connected with indicators of physical training, credit standards of educational program. Due to this many publications contain the idea of necessity to develop such programs and technological models of students' HLS formation by means of physical culture which can substantially improve the problem situation, can change the students' attitude to the health and mode of life. The second reason for improving the situation consists in the fact that our country enters the system of competence education and in order to march in step with higher education modernization it is necessary to rebuild the process of teaching of the discipline named as "Physical culture" and its didactic component "Foundations of healthy life-style" on the base of competence approach. And naturally the question arises: what should be done in order the competence approach being in coordination with the existed innovative concepts and models of students' physical training (proved their practical reasonability) will be used in practical work of the departments of physical culture together with the other approaches (personality-oriented, action approach, differentiated one, etc.). But developing this innovative direction of students HLS formation by means of physical culture it is necessary to realize the resources of university's educational environment: administrative resource (development of corresponding university programs, planning of health supporting arrangements, HLS propaganda, support, financing, control, etc.); resources of educational process (introduction of special HLS course, interdisciplinary relations, organization of physical cultural an health-improving arrangements, cultural-mass and free-time work); utilization of regulated (forms of studies) and non-regulated (different forms of independent work) educational environment potential; the resource of public organizations (trade union, sports club, youth associations, etc.); medical service (regular medical inspection, diagnostics of their level of health, preventive measures, medical support, etc.).

This year at our university there have been formed 68 groups of health for additional studies. Moreover, two times a week students attend physical culture lessons if they wish, they can choose any kind of sport or be trained according to the chosen system of exercises. These studies are conducted under control of teachers and medical staff. We do not only speak about HLS, we provide it in practice.

\section{Conclusion}

Results of the research showed that modern students aspire to support their health. Most tested students consider healthy lifestyle as regular mills, good sleep, going in for sports and denial of unhealthy habits. However, young people do not always follow these simple rules. It is necessary to activate the work of physical culture departments in this direction and to carry out scientific research of this problem. 


\section{References}

[1] E.A. Zhitnickaya, et al., Education priority attention to health as a basis for promoting the formation of healthy-lifestyle of students, Irkutsk, 1991.

[2] T.N. Malyarenko, Valeological aspects of higher education, Valeology 2 (1996).

[3] N.A. Aghajanian, Health of students, Moscow: Izd Rund, 1997.

[4] R.I. Iseman, Russia's health crisis: medical, social, psychological and pedagogical principles for its formation, Novosibirsk: Izd NGPU, 1997.

[5] L.I. Aleshina, Building Motivation healthy lifestyle of the future teachers in the process of professional under-cooking: Author. dis .... Cand. Ped.Science, Volgograd, 1998.

[6] G.L. Apanasenko, Valueology: First Results and Future Prospects, The Theory and Practice of Physical Culture 6 (2001).

[7] V.Y. Salov, Theoretical and methodological foundations of a healthy lifestyle for students, you sredst Physical Education: Author Dr. Ped. Science, SPb., 2001.

[8] O. Vasilyeva, Psychology of human health: standards of presentation of the students, M.: Academia, 2001

[9] V.I. Bondin, School health teacher in higher education, Theory and Practice of Physical Culture 10 (2004).

[10] T.M. Kazin, N.E. Kasatkin, Scientific-methodical and organizational approaches to the creation of a regional program of "education and health, Valeology 4 (2004).

[11] N.A. Bezrykhih, Formation of setting students on a healthy lifestyle in the educational process of professional schools: Dis .... Cand. Ped. Science, Saratov, 2006.

[12] S.A. Ovchinnikov, Physical culture identity as a leading factor in the formation of a healthy lifestyle Student: Author. Cand. Ped. Science, N.Novgorod, 2006.

[13] O. Valiulina, A healthy lifestyle of students in the learning process by means of adaptive physical education: Author. dis .... Cand. Ped. Science, Ufa, 2006.

[14] M.Y. Vilensky, A.G. Pots, Physical education and healthy lifestyles of student: textbook, Benefit, M.: Garuariki, 2007. 